\title{
HAL-HAL YANG ABSEN DALAM PENCATATAN MENGENAI FILM NASIONAL
}

\author{
Tunggul Banjaransari \\ Dosen Program D-4 Film dan Televisi \\ Universitas Dian Nuswantoro Semarang \\ No. Hp.: 082225723525, E-mail: hailfilmcube@gmail.com
}

\begin{abstract}
ABSTRAK
Penulisan narasi besar mengenai film-film nasional lebih sering dilakukan daripada penulisan narasi kecil mengenai film-film di Indonesia. Seperti halnya yang dilakukan oleh para penulis buku berjudul Merayakan Film Nasional (yang ditulis oleh Adrian Jonathan Pasaribu, Hikmat Darmawan, dan Totot Indrarto). Tujuan yang dilakukan tentunya tidak lagi melihat film nasional sebatas teritorial saja, tetapi mendorong pembaca dan pembuat film untuk melepas bebanbeban makna nasional. Dengan demikian, bentuk-bentuk film pascanasional melalui aspek fungsional dan relasionalnya mulai terepresentasikan. Akan tetapi, jika hanya bergantung pada narasi besar, upaya pemaknaan tersebut justru melanggengkan praktik imaji orientalis Barat dalam film-film di Indonesia. Oleh karena itu, narasi kecil yang tidak muncul dalam buku Merayakan Film Nasional harus dilengkapi. Penulisan narasi kecil tersebut dilakukan melalui tiga model analisis: (1) proses reintepretasi mitos pada masyarakat kontemporer dalam film di Indonesia, (2) model reintepretasi realitas sebagai sebuah aksi protes dan komikal dalam film di Indonesia, dan (3) unsur-unsur yang mendorong terjadinya hibrida teks dalam film terkini, sebagai upaya mengubah wajah film di Indonesia yang lebih beragam.
\end{abstract}

Kata kunci: film nasional, film pascanasional, identitas Liyan, lari dari kenyataan

\section{ABSTRACT}

Absent Things in Listing of National Films. The big narration writings of national film has often been done more than the small narration of films in Indonesia. This has been shown by the authors of a book titled 'Merayakan Film Nasional' (Adrian Jonathan Pasaribu, Hikmat Darmawan, and Totot Indrarto). The aim is no longer solely reviewing national film at is territory, but also to encourage the readers and filmmakers to release the burdens of national signification. Therefore, the format of post-national films through the functional and relational aspects has begun to be represented. However, if it merely depends on the big narration, this effort of making meaning would only perpetuate the practice of Western oriental image in Indonesian films. Therefore, the absence of small narration in the book of "Merayakan Film Nasional' should be completed. In this regard, it will be done in three analysis models: (1) process of myth reinterpretation for contemporary citizens in Indonesian films,(2) model of reality's reinterpretation as an act of protests and comical in Indonesian films, and (3) the elements prompting the texts hybrid in recent films, as an attempt to change the image of films in Indonesia to be more diverse.

Keywords: post-national film, the other's identity, running from reality 


\section{PENDAHULUAN}

Artikel ini dibuat sebagai bentuk ungkapan terima kasih dari penulis kepada para penulis buku berjudul Merayakan Film Nasional (selanjutnya disebut sebagai MFN, ditulis oleh Adrian Jonathan Pasaribu, Hikmat Darmawan, dan Totot Indrato). Buku ini diterbitkan atas prakarsa Direktorat Sejarah dan Direktorat Jenderal Kebudayaan di bawah naungan Kementerian Pendidikan dan kebudayaan Indonesia. Karena buku ini, dari perdebatan yang tidak menemukan ujung temu, peneliti film yang kesusahan menemukan acuan, hingga pembuat film yang kehilangan tujuan akhirnya menemukan titik temu mengenai wacana dan orientasi film nasional.

Rasa terima kasih penulis diwujudkan melalui refleksi perayaan film nasional melalui bagaimana mengaktualisasi ajakan merayakan film nasional melalui narasi dan permasalahan film di luar narasi Jakarta? Hal tersebut menjadi penting bagi peneliti karena tidak adanya pembahasan sedikit pun mengenai narasi dan permasalahan film di luar Jakarta. Semua penulis masih terpaku pada aktivitas baik secara historis, politis, maupun sosialbudaya yang terjadi di ibukota tersebut.

Upaya untuk membongkar definisi tunggal mengenai film nasional pernah dilakukan oleh Seno Gumira. Melalui orasinya ${ }^{1}$ yang dilakukan tepat pada Hari Film Nasional tahun 2014, ia memberikan gambaran bahwa film dengan identitas nasional tidak bisa didefinisikan secara tunggal bahwa film tersebut sekadar dibuat di Indonesia, dibuat oleh orang Indonesia, dan bercerita mengenai Indonesia saja (pemaknaan film secara teritorial). Karena definisi tersebut telah tumpang tindih dengan kondisi global yang sarat akan komodifikasi kepentingan tertentu dengan membawa beban makna nasional. Tambahnya, untuk memaknai film haruslah didekati melalui aspek fungsional dan relasional, bukan lagi teritorial (Ajidarma, 2014). Maksudnya, 1 Orasi Seno Gumira secara lengkap dapat dilihat di laman https://vimeo.com/90500526 perkembangan (bentuk) film tidak menutup kemungkinan mengalami pencampuran dengan berbagai aspek dan rumpun di luar elemen-elemen kebangsaan (seperti bentuk cerita dipengaruhi oleh Holywood). Dengan demikian, pemaknaan terhadap film asional harus diubah sesuai dengan perkembangan nilai gunanya.

Upaya untuk membuat wajah film nasional terlihat beragam sebenarnya sudah dilakukan oleh para penulis buku MFN. Pada bab yang ditulis oleh Totot Indrato, ia berusaha menarik rumpun muasal dari film nasional. Mulai dari unsur kepengaruhan film-film Italia, yang kemudian diboyong oleh para pengusaha Cina dan pejabat Belanda untuk memproduksi film di Hindia Belanda. Tentu saja, hal itu memengaruhi bentuk film yang mengalami persilangan dari berbagai rumpun. Dengan demikian, memaknai otentisitas film nasional bermuara pada film Darah dan Doa ${ }^{2}$ (Ismail, 1950) merupakan kesalahan yang besar karena hanya akan berkutat pada definisi teritorial. Totot menarik rumpun keragaman film Indonesia ini jauh ke belakang sebelum film Darah dan Doa dibuat dan dipertontonkan.

Dalam bab yang ditulis oleh Adrian Jonathan Pasaribu, ia berusaha menggambarkan bahwa film sebagai praktik politik pun memiliki keragaman tersendiri. Hal itu terlihat pada salah satu agenda kegiatan LEKRA dalam memproduksi film. Pasca-1965, melalui rezim Orde Baru, film dikendalikan secara penuh baik pada urusan produksi, distribusi, hingga persoalan selera masyarakat sekalipun (Sen, 2009). Dengan demikian, melegitimasi film nasional pada ciri khas tertentu memang harus ditelaah ulang, mengingat aspek historis politiknya, Indonesia mengalami dualisme bentuk pemerintahan.

2 Film Darah dan Doa merupakan film pertama yang dibuat/disutradarai oleh orang Indonesia bernama Usmar Ismail. Hari pertama pelaksanaan produksi film ini (30 Maret 1950) dicetuskan oleh Soekarno sebagai Hari Film Nasional. 
Peran Hikmat Darmawan dalam buku ini menjadi penarik benang merah di antara dua penulis lainnya. Ia menjelaskan bahwa film nasional yang belum tentu juga film di Indonesia ini dibentuk melalui tiga bentuk sejarah. Pertama, sejarah media, film sebagai bagian dari alat diplomasi, komunikasi terhadap penonton yang luas. Kedua, sejarah sosial, film dijadikan sebagai bagian untuk mendaur ulang cerita-cerita rakyat yang ada di Nusantara. Fungsinya adalah mereproduksi makna-makna sosial yang terkandung dalam tradisi tertentu di Indonesia. Ketiga adalah, sejarah politik, di poin ini Hikmat bersikap senada dengan apa yang dituliskan oleh Adrian.

Dari kumpulan tulisan tersebut, terlihat bahwa sebenarnya pembaca dibawa untuk melihat keragaman film di Indonesia melalui aspek kesejarahannya. Namun, kesemuanya belum mewakili dinamika masyarakat Indonesia secara luas karena dalam buku $M F N$, hal yang dibingkai hanyalah aktivitas politik dan sedikit kebudayaan urban. Mengutip apa yang dijelaskan oleh Seno mengenai pendekatan relasional dan fungsional, digabungkan dengan reproduksi makna sosial yang dijelaskan oleh Hikmat, tulisan ini mencoba membingkai beberapa hal yang belum dicatat sebagai keragaman film di Indonesia, melalui tiga hal. Pertama, penulis membahas proses reinterpretasi mitos pada masyarakat kontemporer dalam film di Indonesia. Kedua, pembahasan mengenai re-interpretasi realitas sebagai sebuah aksi protes dan komikal dalam film di Indonesia. Ketiga, penulis membahas unsur-unsur yang mendorong terjadinya hibrida teks dalam film terkini, sebagai upaya mengubah wajah film di Indonesia yang lebih beragam.

\section{NARASI GAIB DALAM FILM SEBAGAI PRAKTIK POLITIK YANG LIYAN}

Flannery O'Connor mengatakan bahwa kesalahan terbesar manusia adalah bernostalgia. Hal ini masih relevan untuk menggambarkan relasi kuasa negara terhadap masyarakat melalui film. Kondisi pascanasional seperti yang dikatakan oleh Seno dalam orasinya, bukan berarti menandakan bahwa seseorang ataupun masyarakat terbebas dari beban makna kebangsaan. Pengaruh kuasa akan terus berkelindan dan bertransformasi dengan cara yang lebih halus daripada sebelumnya. Di Eropa Barat, permasalahan klasik kuasa negara terhadap sinema terus bergulir. Bentuknya, bukan lagi sebagai sebuah sistem yang mengendalikan secara penuh bentuk film dan tata edarannya, melainkan malah menjadikan film sebagai alat untuk branding, alat marketing, entitas lokal yang ada di dalam sebuah negara (Elsaesser, 2013).

Masih dalam artikel yang sama, Elsaesser menjelaskan contohnya melalui film berjudul Run Lola Run (Tykwer, 1998). Secara khusus, film tersebut tidak bercerita mengenai Berlin sebagai wilayah yang bagus untuk dikunjungi wisatawan. Akan tetapi, melalui kerja kamera yang selalu mengikuti karakter Lola berlari menyusuri jalanan Berlin, pesona yang dihadirkan oleh Berlin dan Jerman begitu menawan.

Sebenarnya bukan hanya sebagai branding wilayah secara fisik, tetapi juga branding wilayah secara tingkat keramahannya (hospitality) terhadap hal-hal tertentu. Misalnya dalam film berjudul Dheepan (Audiard, 2015). Film tersebut membingkai Prancis sebagai sebuah negara yang ramah dengan para pencari suaka politik. Dalam film ini, seorang berkewarganegaraan Sri Lanka dan mantan pejuang Tamil memutuskan untuk pindah ke Prancis dan menjadi perawat lansia di sebuah kota di Prancis. Ia harus bergelut dengan mengubur dalam-dalam masa lalunya yang kelam 
di Sri Lanka, dan mengubah hidupnya sekaligus menjadi warga negara Prancis. Wilayah Prancis digambarkan begitu tenang dan damai dalam film itu. Ketegangan hanya terjadi antara Dheepan dan kondisi traumanya menjadi pejuang Tamil pada masa lalu.

Cara-cara negara untuk membangun identitas pascanasional melalui berafiliasi dengan pembuat film di kawasan Eropa sangatlah halus. Di Indonesia, hal tersebut bisa ditemukan dalam film horor. Memang, format lama (era Orde Baru) film horor sudah tidak digunakan. Caranya melalui menghilangkan karakter kyai, ulama, atau ustaz yang dijadikan sosok sebagai pengusir ataupun pembunuh hantu (Heeren van, 2012). Setelah Orde Baru, film-film horor menghilangkan karakter tersebut, tetapi terdapat hal yang masih tetap dipertahankan. Hilangnya sosok kyai membuat karakter-karakter utama yang dihantui menjadi kehilangan arah dan tidak memiliki daya untuk melawan hantu-hantu tersebut.

Terlebih lagi, sosok hantu yang diidentikkan sebagai jelmaan manusia yang meninggal secara mengenaskan pada masa lalu ini sebenarnya merepresentasikan posisi negara (kuasa masa lalu) yang menakutkan bagi generasi muda. Sayangnya, film horor yang umumnya memakai anak muda sebagai karakter utama ini pun ditempatkan takluk pada kekuatan tersebut, tidak berdaya melawan, atau harus mematuhi standar kepatuhan agar tidak ditakuti lagi.

Beberapa kalangan menganggap bahwa film berjudul Pengabdi Setan yang direproduksi oleh Joko Anwar merupakan film yang berhasil mengubah format film horor. Pasalnya, kehadiran sosok ustaz yang tidak berguna sama sekali dalam mengusir hantu dan malah terbunuh, dianggap bahwa penggambaran ustaz merupakan bagian dari manusia pada umumnya. Bukan sosok yang selalu mampu menyelesaikan permasalahan dalam film.
Akan tetapi, bagaimana dengan penggambaran kelompok sekte di dalamnya? Melalui penyikapan cerita, kamera, dan sisi pewarnaan gambar, kelompok ini seolah-olah digambarkan menjadi kelompok yang membahayakan dan menakuti keberadaan atau keutuhan sebuah keluarga yang seharusnya harmonis. Bukankah hal tersebut merupakan gambaran sikap yang sama seperti pemerintah Indonesia terhadap keragaman sistem keyakinan selain lima agama yang dinyatakan sah? Maka itu, film ini cukup berkontribusi mengukuhkan identitas pascanasional Indonesia secara halus.

Tidak ada keliyanan dalam film horor di Indonesia yang erat sekali dengan penguatan identitas negara sebagai penguasa. Selama ini, karakter yang mempresentasikan masyarakat dibuat tertata sesuai dengan standar kehidupan yang dimaksud oleh penguasa. Hal-hal yang menjadi masalah merupakan hal-hal yang datangnya dari luar lingkup negara ini, seperti minuman beralkohol, pornografi, aksi protes anak muda selalu dilekatkan dengan budaya Barat yang tidak sesuai dengan budaya Nusantara/Timur. Padahal, untuk menghasilkan pemaknaan baru, individu memerlukan sebuah ide yang baru bahkan berlawanan dengan sistem yang diterapkan dalam sebuah kelompok. Dengan demikian, relasi antarindividu di dalamnya tidak hanya berjalan secara simbolis, melainkan adanya benturan yang menghasilkan pihak yang liyan ${ }^{3}$ (Rokhani, 2016). Kehadiran sosok liyan dalam kelompok atau masyarakat inilah yang mendorong adanya keragaman pandangan, bentuk, dan film.

Terdapat satu film pendek yang bagi penulis memiliki upaya pemaknaan baru mengenai relasi liyan dengan negara. Film tersebut berjudul Anggarbini. Film ini disutradarai oleh M. Ghaida Akbar, seorang mahasiswa UIN Yogyakarta yang tergabung dalam kelompok Jama'ah Cinema Mahasiswa UIN (JCM UIN). Film ini mengambil

$3 \quad$ Periksa juga (Beauvior, 2003) 
sebuah situasi di suatu desa yang sedang menghadapi proses pemilihan kepala kelurahan (lurah). Pada situasi ini, satu desa digemparkan dengan kabar bahwa anak perempuan salah seorang calon lurah (lurah incumbent) hamil di luar pernikahan. Ayahnya berusaha menutupi kabar tentang siapa yang menghamili anaknya tersebut. Cara menutupinya adalah dengan membuat narasi fiktif berupa anaknya telah dihamili oleh jin. Ia menyebarkan kabar tersebut melalui dua orang yang menjadi aktor sosial dalam dua kelompok yang berbeda, kelompok agama (melalui majelis masjid) dan kelompok petani (Akbar, 2018).

Narasi ini berhasil meyakinkan sebagian besar warga, dikuatkan pula terdapat kejadian salah seorang anak pria disunat oleh jin. Lurah tersebut memelintirkan narasi mengenai keberadaan jin dengan pelbagai kejadian sebagai bentuk keberkahan di desa ini. Sebagian kecil warga menyadari adanya kejanggalan ini. Mereka membentuk kelompok kecil dan mulai menggerakkan dan menyadarkan sebagian besar warga bahwa narasi mengenai jin hanya untuk menutupi aib. Menariknya lagi, kelompok kecil ini juga meluruskan kejadian tersebut sebagai bentuk atau modus melanggengkan praktik kekuasaannya pada saat proses kampanye sedang berlangsung. Kejelian kelompok kecil terhadap permasalahan inilah yang jarang dibingkai dalam film di Indonesia. Umumnya, aksi protes hanya berhenti di titik penguasa memberikan asumsi bahwa itu bukan tanggung jawab mereka atau melalui kekerasan melalui aparat militer atau polisi terhadap aksi protes. Kemudian, diakhiri dengan karakter yang melakukan aksi protes dikembalikan ke jalan yang benar.

Karakter kelompok kecil dalam film Anggarbini berhasil menampilkan sosok liyan di antara relasi masyarakat dengan penguasa. Hal ini penting sebagai gambaran sebuah reaksi protes terhadap upaya untuk menjadi liyan di antara standar kepatuhan terhadap masyarakat. Film ini menjadi penting untuk dipertontonkan kepada masyarakat di Indonesia, sebagai sebuah alternatif pengetahuan mengenai keberadaan ide-ide individu yang perlu dikelola dan dijadikan sebagai bahan diskursus.

\section{MABUR DI ATAS LAUT KECIL}

Pendekatan fungsional dan relasional tidak lantas menjadi satu-satunya cara untuk membentuk sebuah formula film yang tepat. Mattias Frey berpendapat bahwa kondisi penonton global tidaklah sama dalam artian pilihan tontonan dan selera yang sama, antara penonton di negara tertentu dengan penonton di negara lainnya, tetapi penonton sudah terkotakkan berdasarkan imaji Barat mengenai wilayah tertentu (Frey, 2016). Misalnya, kritik Frey terhadap film Rashomon (Kurosawa, 1950). Pada satu sisi film ini menampilkan sebuah budaya pada era samurai tertentu di Jepang, tetapi pada sisi yang lain film ini menampilkan perayaan aksi pemerkosaan. Hal tersebut merujuk pada imaji orientalis Barat mengenai budaya Asia dan perilaku masyarakatnya ${ }^{4}$.

Dengan demikian, dorongan untuk memaknai kembali terkait film menggunakan pendekatan fungsional dan relasional juga memiliki konsekuensi untuk menciptakan jarak dengan budaya tertentu pula. Oleh apa yang diimajinasikan orientalis Barat mengenai Indonesia tidak lepas dari kemiskinan manusianya, perilaku bar-bar di antara manusianya, tata kota dan fasilitas publik yang semrawut, gali lubang-tutup lubang untuk mencukupi kebutuhan. Imajinasi seperti itu memang sangat bisa ditemukan di wilayah urban di Indonesia. Akan tetapi, bukankah itu sebuah perubahan yang terjadi dalam masyarakat Indonesia, ketika pemerintah Indonesia gemar mengadopsi tata pembangunan termutakhir ala Barat?

$4 \quad$ Periksa Anderson \& Richie (1959) dan de Bary \& Burch (1982) 
Penggunaan imaji Barat ini terbukti memberikan keuntungan bagi beberapa pembuat film di Indonesia. Misalnya film Prenjak (Bhanuteja, 2016) menampilkan sebuah peristiwa yang sangat mendesak dari seorang perempuan muda berbehel untuk mencukupi kebutuhannya. Dengan pendapatan yang sedikit sebagai pelayan di sebuah restoran pizza, ia harus menjual vaginanya kepada rekan kerja. Caranya, ia mempersilakan rekan kerjanya melihat alat kelamin dalam beberapa detik saja menggunakan korek api. Melihat vagina menggunakan korek api ini sebagai sebuah cara untuk merepresentasikan kejadian yang tabu di Indonesia. Seorang pelanggan baru bisa mengakses sesuatu yang dianggap tabu melalui cara-cara yang tidak terlihat. Imaji Barat ini semakin ditegaskan dengan keberhasilan film ini meraih penghargaan sebagai film pendek terbaik di Cannes Film Festival 2016, sesi Semaine de la Critique.

Sebuah film dapat digubah sedemikian rupa dari yang seharusnya menghasilkan kesan buruk menjadi sebuah formula yang mempresentasikan realita tertentu (Lübecker, 2015). Dari terapan itu, terdapat film di Indonesia yang mendorong penontonnya merasakan kesan yang bosan menjalani kehidupan seorang pegawai di toko penjualan mebel. Film ini berjudul Vakansi yang Janggal dan Penyakit Lainnya (Noen, 2012). Film tersebut menggunakan tempo yang sangat lambat, pergantian dari gambar satu ke gambar yang lainnya sangat lama jaraknya. Semua aktivitas berjalan lambat, hingga karakter-karakter di dalamnya menemukan sebuah cara untuk menaikkan tempo hidupnya atau menaikkan adrenalinnya untuk berselingkuh. Film ini seolah-olah menggambarkan bahwa tidak ada tempat yang menyenangkan bagi seorang pekerja dengan pendapatan yang pas-pasan. Coba kalau mereka bisa kaya raya, tidak akan menjalani kehidupan yang lambat. Kesimpulannya adalah menjadi miskin dalam film ini (atau bisa jadi di Indonesia) sangatlah dekat dengan hal-hal yang negatif; seperti bosan, melakukan perselingkuhan, dan berutang.

Film-film seperti contoh tersebut telah kehilangan daya protesnya terhadap realitas, malah merayakan realitas yang dibangun dari imaji orientalis Barat (Forrest, 2015). Atau bisa juga disebut bahwa para pembuat film ini tidak memiliki sikap tersendiri atas medium sebagai tempatnya untuk membicarakan persoalan tertentu. Dalam bab yang dituliskan oleh Forest, ia menggambarkan film-film Hanneke yang gemar menunjukkan utopia yang negatif masyarakat Eropa Barat di filmnya. Hanneke menampilkan filmnya seperti horor, tetapi berjalan begitu lambat. Hal ini dilakukan sebagai cara untuk memutarbalikkan imaji mengenai masyarakat Eropa yang maju dan beradab (Forrest, 2015). Hal yang disajikan adalah masyarakat Eropa yang tertekan dan tidak memiliki tempat untuk bersenang-senang. Pendekatan film dengan tempo yang lambat justru terasa tepat diterapkan untuk menggambarkan masyarakat Eropa Barat.

Dalam film berjudul Siti, sebenarnya menerapkan hal yang serupa dengan apa yang dilakukan oleh Wregas Bhanuteja dan Yosep Anggi Noen. Tokoh Siti harus menjadi tulang punggung keluarga karena suaminya lumpuh. Selama filmnya, penonton disajikan gambar dan suara yang amat menekan Siti, atau sejatinya tidak ada tempat bagi Siti. Akan tetapi, di bagian akhir film ini terdapat hal yang menarik bagi penulis. Tokoh Siti yang tinggal di pesisir pantai selatan Jawa, berjalan menuju tengah laut dan menghilang. Hal ini merupakan cara Siti melalui pembuat filmnya untuk lari dari kenyataan tersebut.

Karena pendekatan relasional dan fungsional yang ternyata memiliki konsekuensi permasalahan yang besar, penulis melengkapi model tersebut dengan model film yang lari dari kenyataan. Terdapat dua film yang dijadikan 
sampel atas kemampuan film tersebut yang mampu mempresentasikan mediumnya sebagai upaya untuk terlepas dari beban-beban realitas. Film tersebut berjudul Mabur (Sukma, 2018) dan Laut Kecilku (Wulandari, 2018). Kedua film ini mencoba memaknai ulang mengenai ruang sempit sebagai tempat hidup masyarakat (kelas menengah-bawah di Indonesia) yang tidak melulu menghasilkan sesuatu yang negatif. Seperti kemiskinan yang mencekam dan menghasilkan perilaku yang bar-bar, serta aktivitas seksual sebagai satu-satunya cara untuk keluar dari impitan tersebut. Akan tetapi, kedua film ini berhasil menemukan sisi yang komikal dari ruang dan situasi yang serba menyempitkan.

Dalam film Mabur, seorang pelajar SMA meminta ibunya membayar iuran study tour ke Bali. Ibunya yang menjadi pelayan sebuah warung makan yang dihias perabot-perabot vintage merasa keberatan dan tidak mau membayar iuran tersebut. Ibunya menyarankan anaknya pergi ke pamannya yang seorang dukun, meminta sesuatu agar dapat menggantikan keikutsertaannya pergi piknik bersama sekolahnya. Dari situasi dan ruang yang sempit ini, Abi Sukma mengubahnya menjadi situasi yang komikal ketika sang anak mendatangi rumah pamannya yang memiliki kemampuan supranatural tersebut (dukun). Alih-alih menerapkan adegan yang horor dan mencekam seperti gambaran adegan rumah paranormal pada umumnya, justru Abi Sukma membuat relasi antara paman (dukun) dan keponakannya yang sangat cair. Malah, seseorang yang memegang kendali atas praktik supranatural adalah anaknya, pamannya banyak dicibir karena meremehkan seorang anak SMA yang memiliki ide untuk menerbangkan jiwanya guna menghasilkan imaji mengenai liburan. Ilmu dan tata caranya diperoleh anak tersebut, pulanglah dia dan mempraktekannya. Alhasil, di dalam kamarnya yang sempit, semrawut, dan menjadi satu dengan kamar ibunya, ia bertapa dan mengutarakan jimat digubah menjadi lagu pop. Pada gambar berikutnya, penonton dibawa masuk ke dalam imajinya mengenai liburan melintasi polusi udara, kebisingan suara pabrik, dan menikmati kuburan yang tertata rapi dengan identitas agama yang beragam (Kristen, Katolik, Yahudi, dan Islam).

Dalam film berjudul Laut Kecilku, seorang anak berusia 10 tahun menjalani hari-harinya hanya sendiri tanpa dampingan orang tua di sebuah rumah susun. Orang tuanya baru bisa mendampingi selepas mereka bekerja sebagai buruh pabrik menjelang malam hari. Di dalam flat yang berukuran sangat kecil, anak ini menghabiskan waktunya dengan menonton televisi mengenai dunia di dalam laut. Karena saking penasarannya dengan dunia yang hampir tidak terjamah sebagian besar manusia ini, ia menciptakan dunia tersebut melalui imajinya sendiri. Ia menggunting kertas minyak bekas tempat gorengan yang ia makan menjadi ikan-ikan laut, terumbu karang, dan biota laut lainnya. Belum puas dengan itu, ia gunakan tabungan yang ia kumpulkan tiap hari untuk membeli kostum mermaid. Lalu, ia pakai sebuah bak mandi berukuran anak kecil, ia beri pasir pseudo pantai, rumput laut (dari butiran bumbu rumput laut snack instan), ia masukkan biotabiota yang ia ciptakan tadi. Hasilnya, bak tersebut menjadi keruh, biota hancur, ia tetap berenang.

Kedua film tersebut memiliki formula yang sama. Mereka membagi filmnya menjadi dua subbentuk; subbentuk pertama adalah menghadirkan ruang yang sempit bagi karakter-karakternya. Pada bentuk pertama ini pembuat film menjalankan filmnya bukan dari sosok karakter yang sedang berjuang atas nasibnya, tetapi ruang. Ruang seperti kamar dan warung yang mempresentasikan kelas menengah-bawah (film Mabur) dan ruang flat rumah susun yang sangat sempit. Baru kemudian, pada subbentuk kedua; mereka menghadirkan karakter-karakter yang mencoba mengakali ruang dan persoalannya menjadi sesuatu yang liyan. 
Bukan sebagai tempat rutinitas lagi, tetapi sebagai cara untuk lari dari kenyataan itu sendiri. Bentuk kedua film ini tidak baru seutuhnya, mereka masih mengadopsi dan mengadaptasi bentuk-bentuk yang sudah ada seperti cara bertutut film di Indonesia yang menggunakan imaji orientalis Barat. Kemudian digabungkan dengan kesan komikal yang sering dipakai Jacques Tati dalam film-filmnya (khususnya Mon Oncle, 1958) dan Charlie Caplin (khususnya Modern Times, 1936).

\section{SIMPULAN}

Indonesia merupakan negara yang luas, begitu juga dengan permasalahan yang ada di dalamnya. Dalam sejarahnya, keragaman tersebut sebenarnya sudah tampak. Tidak hanya persoalan pentasbihan identitas tertentu, tetapi juga kondisikondisi yang depresif. Sazkia menjelaskan fenomena keragaman tersebut sebagai refleksi kegalauan (Anggraini, 2015). Para penulis buku MFN memang tidak bermaksud untuk menyingkirkan narasi kecil mengenai film di Indonesia. Justru, melalui pendekatan dalam aspek kesejarahan film, telah membukakan pintu bagi para peneliti dan khususnya penulis artikel ini untuk melengkapi narasi kecil mengenai film di Indonesia. Agar pengetahuan mengenai film di Indonesia tidak terbatas pada praktik politik negara dan masyarakatnya, melainkan pada hal lain yang sifatnya lebih luas film nasional, praktik untuk mengembangkan film pascanasional dapat dilakukan lebih luwes, tidak hanya berkelindan dalam beban-beban pemaknaan identitas bangsa belaka.

Untuk mengupayakan formula atau bentuk film pascanasional, tidak hanya mentah-mentah menerima pendekatan relasional dan fungsional. Justru pendekatan tersebut juga memiliki konsekuensi besar untuk menjadikan pembuat film menggunakan imaji orientalis Barat sebagai sikap dalam membentuk filmnya. Pendekatan tersebut harus senantiasa diintepretasikan berulangulang kali. Hingga menghasilkan bentuk-bentuk yang mempresentasikan imaji yang liyan sebagai individu (pembuat film). Seperti yang dikatakan oleh Alexander Kluge bahwa film itu menjadi alat untuk protes. Film menjadi media untuk berbicara mengenai hal-hal yang membuat gelisah seseorang. Protes-protes tersebut tentunya hadir dalam bentuk kejelian seseorang menemukan hal yang dianggapnya bermasalah, berpotensi menghasilkan diskriminasi, dan adanya kesewenang-wenangan. Alhasil, dirinya membentuk sebuah alternatif ruang untuk melepas dari beban-beban kepatuhan terhadap sebuah sistem yang menata kehidupan. Realitas memang perlu direspons sedemikian rupa dan disikapi hingga menghasilkan film.

Dalam tulisan ini, penulis melengkapi model pendekatan relasional dan fungsional dengan pendekatan bentuk lari dari kenyataan melalui medium film. Terdapat dua film yang menjadi alat analisisnya. Kedua film tersebut berjudul Mabur (disutradarai oleh Abi Sukma) dan Laut Kecilku (disutradarai oleh Sarah Putri). Kedua film itu memiliki formula yang sama, bahwa keduanya tidak sepakat bahwa ruang-ruang yang sempit harus dirayakan sebagai realitas film (hal itu terjadi dalam realitas saja). Akan tetapi, mereka mengubah imaji mengenai ruang yang sempit menjadi situasi yang komikal, mengubah kesan mengenai kemiskinan yang erat dengan hal-hal yang negatif, menjadi kesan satir dicampur dengan sarkas, dan parodi dalam filmnya. Menonton setengah bagian dari kedua film tersebut seperti menonton film-film Jacques Tati dan Charlie Caplin. 


\section{KEPUSTAKAAN}

Ajidarma, S. G. (2014). Film Indonesia dan Identitas Nasional dalam Kondisi Pascanasional. Retrieved from https://vimeo.com/90500526 Akbar, G. (2018). Anggarbini. Indonesia.

Anderson, J. L., \& Richie, D. (1959). The Japanese Film: Art and Industry. Michigan: The University of Michigan.

Audiard, J. (2015). Dheepan. Prancis.

Beauvior, S. de. (2003). Second Sex: Fakta dan Mitos. Surabaya: Pustaka Promethea.

Bhanuteja, W. (2016). Prenjak (In The Year of Monkey). Indonesia.

de Bary, B., \& Burch, N. (1982). To the Distant Observer: Form and Meaning in the Japanese Cinema. Journal of Japanese Studies. https:// doi.org/10.2307/132349

Elsaesser, T. (2013). ImperSonations: National Cinema, Historical Imaginaries, and New Cinema Europe. Mise Au Point, 5. Retrieved from https://journals.openedition.org/ map/ 1480

Forrest, T. (2015). Realism as Protest: Kluge, Schlingensief, Haneke. Bielefeld: Transcript Verlag.

Frey, M. (2016). Extreme cinema: The transgressive rhetoric of today's art film culture. In Extreme Cinema: The Transgressive Rhetoric of Today'S Art Film Culture.

Heeren van, K. (2012). Contemporary Indonesian Film; Spirits of Reform and ghosts from the past. Contemporary Indonesian Film; Spirits of Reform and Ghosts from the Past. https:// doi.org/10.26530/oapen_420331

Ismail, U. (1950). Darah dan Doa. Indonesia.

Kurosawa, A. (1950). Rashomon. Japan.

Lübecker, N. (2015). The Feel-Bad Film. In The Feel-Bad Film. Edinburgh: Edinburgh University Press.
Noen, Y. A. (2012). Vakansi yang Janggal dan Penyakit Lainnya. Indonesia.

Sen, K. (2009). Kuasa dalam Sinema: Negara, Masyarakat, dan Sinema Orde Bar. Yogyakarta: Yayasan Ombak.

Sukma, A. (2018). Mabur Dhuwur Maring Bumi. Indonesia.

Tykwer, T. (1998). Run Lola Run. Jerman.

Wulandari, S. P. (2018). Laut Kecilku. Indonesia. 
